\title{
ATRIBUTOS MORFOLÓGICOS E VEGETAIS INDICADORES DE QUALIDADE DOS SOLOS DO BALNEÁRIO MOUSINHO, VARGEM GRANDE - MA
}

\author{
Ana Raissa de Oliveira Gomes ${ }^{(a)}$, Elaine Cunha Vieira ${ }^{(b)}$, Marcelino Silva Farias Filho ${ }^{(c)}$ \\ (a) Acadêmica de Geografia, Universidade Federal do Maranhão, raissagomes90@gmail.com \\ (b) Acadêmica de Geografia, Universidade Federal do Maranhão, elai.cv@ @otmail.com \\ (c) Professor Doutor do Departamento de Geociências, Universidade Federal do Maranhão, marcelinofarias@ufma.br
}

\section{EIXO: SOLOS E PAISAGENS}

\begin{abstract}
Resumo
O presente trabalho analisa os solos do Balneário Mousinho localizado no município de Vargem Grande por meio dos seus atributos morfológicos. Analisa também as principais atividades desenvolvidas no local e problemas ambientais por elas ocasionadas. A pesquisa foi desenvolvida com base em levantamento bibliográfico e em observações in situ realizadas em aulas de campo desenvolvidas no âmbito do curso de Geografia na Universidade Federal do Maranhão. No Balneário, os solos são ácidos, marcados pela presença de argilas do grupo das caulinitas, o que proporciona o desenvolvimento da atividade ceramista e restringe as práticas agrícolas. É marcante a presença do babaçu devido às práticas de manejo do solo associadas à implantação de pastagens e roças que têm ocasionado compactação do solo e supressão e simplificação da cobertura vegetal original.
\end{abstract}

Palavras chave: Atributos morfológicos. Práticas Agrícolas. Balneário Mousinho (Vargem Grande MA)

\section{Introdução}

Estudar o solo em sua complexidade é importante por vários motivos, dentre os quais destacam-se a previsão de futuros problemas, o estabelecimentos de atividades condizentes com a classe de solo, a análise do tipo de vegetação e atividades econômicas desenvolvidas entre outros. Vargem Grande, município localizado na porção nordeste do estado do Maranhão, apresenta uma variabilidade grande de classes de solos, representados, predominantemente, por Latossolo Amarelo que são profundos e bem drenados, Planossolos e Plintossolos que apresentam restrição à percolação da água. Estes solos abrigam cobertura vegetal marcada por traços do bioma cerrado, com o domínio de babaçu (Orbignya speciosa) que foi favorecido pelo uso do fogo na implantação de sistemas agrícolas (roça) e de pastagens.

A partir destes solos, desenvolvem-se atividades como cerâmica, agropecuária e extrativismo, especialmente o do babaçu. As referidas atividades permitem o desenvolvimento de práticas de manejo que resultam em perdas de sedimentos e da do próprio solo, na sua degradação física e empobrecimento químico, pois a maioria dos estabelecimentos da agricultura familiar utiliza o sistema tradicional da agricultura. Assim, o presente trabalho analisou os atributos morfológicos dos solos e problemas ambientais 
relacionados à supressão da cobertura vegetal no Balneário Mousinho, localizado no município de Vargem Grande no Estado do Maranhão.

\section{Metodologia}

Para o estudo foi selecionada a área de proteção ambiental do reservatório de captação de água potável para a cidade de Vargem Grande, o Balneário do Mousinho, situado entre as coordenadas 3³3'40.3"S 4356'57.0"W. A pesquisa foi desenvolvida com base em material bibliográfico e observações in situ com trabalho de campo realizado no mês de agosto do ano de 2016 com parte das atividades de campo da disciplina de Pedologia do curso de Geografia da Universidade Federal do Maranhão.

\section{Resultados Parciais e Discussões}

O município de Vargem Grande está situado na mesorregião Norte maranhense e na microrregião Itapecuru Mirim, abrangendo uma área total de $1.957,751 \mathrm{~km}^{2}$ ocupada por uma população de 49.412 habitantes (IBGE, 2010). De acordo com Correia Filho (2011), o Norte Maranhense compreende o litoral, a Baixada Maranhense, tabuleiros, planície litorânea e fluviais, com altitudes inferiores a 200 metros. A região caracteriza-se pela presença de depósitos sedimentares da Formação Codó, Formação Itapecuru, Formação Barreiras e Depósitos Aluvionares.

Conforme EMBRAPA (2006), os solos predominantes do município são Latossolo Amarelo, Plintossolos e Planossolos. Ainda segundo o autor, Latossolos Amarelos são solos profundos de material argiloso apresentando condições favoráveis de drenagem. Os Planossolos compreendem solos pouco profundos e mal drenados e os Plintossolos caracterizam-se por solos minerais com restrições a percolação da água (JACOMINE et al., 1986).

O município de Vargem Grande tem como principal atividade econômica a cerâmica devido à presença marcante de argilas do grupo das caulinitas (tipo 1:1) nos solos da região. Argila de baixa atividade quando queimada e desidratada plenamente não origina fendilhamento que é o que se deseja na indústria cerâmica, pois permite a fabricação de telhas e tijolos. Por outro lado, essas mesmas argilas originam forte acidez aos solos locais, fato que restringe o desenvolvimento da agropecuária.

A região evidencia o bioma do tipo cerrado, apresentando árvores com sinais de intoxicação devido ao excesso de alumínio trocável presente nos solos. A composição florística é dada em sua grande maioria por leguminosas, a exemplo do pau marfim e ipê, que são plantas que se adaptam às condições de acidez dos solos. Isso se manifesta porque a vegetação é o principal bioindicador de qualidade do solo. Na cobertura 
vegetal observa-se também a carnaúba (Copernicia prunifera), indicador de elevada salinidade do solo e de babaçu (Orbignya speciosa), indicador de acidez e degradação ambiental pelo uso constante do sistema de corte e queima da vegetação. Esse indicador de salinidade deve-se em razão da Formação Itapecuru, constituído por deposição fluviomarinho, onde se formam depósitos de sais, principalmente de cloreto de sódio, que fica acumulado no solo refletindo na vegetação. De outro modo, as briófitas (limo) existentes na carnaúba indicam nível elevado de precipitação e umidade do ar.

A presença do junco (Commons Wikispecies Juncus) em áreas rebaixadas, semelhante à carnaúba é um sinalizador de salinidade, entretanto também um indicador de compactação por ser uma área muito visitada por animais em busca de forragem e de água. O pisoteio do animal é responsável por disseminar a vegetação, por os cascos subdividem as touceiras e fazem com que perfilhos sejam transportados para as áreas do entorno pelos próprios animais, vento ou ação da água. A planta apresenta oxalato de potássio, substância que gera abrasão que inibe o seu uso como forragem, visto que o seu consumo pelo animal faz com que haja desgaste da dentição, o que incorrerá em graves problemas à mastigação e nutrição.

Há também a presença marcante do babaçu (Orbignya speciosa) devido ao desmatamento da cobertura vegetal original e ao uso do fogo (que favorecem a espécie em detrimentos das outras presentes na vegetação clímax) e a baixa fertilidade do solo. A sua presença também se deve ao manejo do solo através da roça e/ou pastagem. Entretanto, nota-se a ausência da vida vegetal em algumas colinas, a exemplo das áreas denominadas pela população local de "morro pelado" (descrição de inselberg cujo material mais superficial forma Neossolo litólico ou litoplintico), com o solo pobre.

O babaçu auxilia na conservação dos sedimentos junto à superfície, apesar de ser uma planta problemática para quem trabalha com agricultura por enraizar muito e endurecer o solo na camada superficial. Esse benefício é importante na área estudada porque, no processo de denudação, os sedimentos do horizonte A vão sendo erodidos, ficando apenas a laterita facilitando o escoamento e erosão dos sedimentos mais finos. Um dos problemas relacionados ao solo dá-se pelo elevado grau de intemperismo associado a elevadas temperaturas e umidade da região. Por ser um solo rico em caulinita, logo mal estruturado, a água não se mantém junto à superfície por muito tempo, sendo conduzida para as regiões mais baixas, momento em que a erosão é favorecida. No mês de agosto (término do período chuvoso), observa-se a vegetação "caducando" em função das perdas hídricas e da baixa retenção de água no solo.

As características das árvores são predominantemente com porte baixo, aspecto tortuoso do caule e folhas grosseiras (coreáceas), indicando intoxicação por alumínio. As folhas das plantas são amareladas (indicando deficiência de nitrogênio) ou avermelhadas (deficiência de fósforo). O nitrogênio disponível para as plantas nos solos de regiões tropicais é proveniente de material orgânico em decomposição ou de fixação biológica de nitrogênio $(\mathrm{FBN})$ por bactérias diazotróficas que fixam do ar atmosférico em simbiose com as plantas 
(leguminosas e gramíneas) e da mineração de $\mathrm{N}_{2}$ por raios que ocorrem frequentemente nos períodos chuvosos. Em solos enriquecidos por óxido de ferro, caso típico dos de Vargem Grande.

A casca grossa das plantas, sinônimo de intoxicação, é essencial pra planta nos períodos secos, pois na estiagem é comum a ocorrência de incêndios no cerrado, promovido pelo homem ou de forma natural. Quando há incêndio, a casca grossa protege a planta da carbonização no momento da queima fazendo com que ela resista às elevadas temperaturas. Contudo, o poder de rebrota das plantas do cerrado tem permitido o desenvolvimento de incêndios criminosos para a promoção da pecuária extensiva e da caça de animais silvestres em extensas áreas.

Nesse período, os animais estão distribuídos ao longo do território na área alta. Ao final da tarde os moradores que são caçadores ateiam fogo em toda área e os animais se encaminham para o vale para se protegerem e terem acesso à água e a um ambiente seguro. Consequentemente os moradores colocam armadilhas na intenção de capturá-los, a exemplo da cutia (Dasyprocta), paca (Cuniculus paca), tatu (Dasypodidae), gato maracajá (Leopardus wiedii) e catitu (Pecari tajacu).

Outra estratégia adotada por eles se dá em função da pecuária, o que favorece o domínio do babaçu em extensas áreas. Os animais, normalmente bovino, ovinos e caprinos são distribuídos ao longo do lago nos vales úmidos onde há pastagens no período chuvoso. Entretanto, no período de estiagem a pastagem acaba e os moradores ateiam fogo nas áreas altas para que os animais tenham disponíveis os brotos para forragem. Por ser uma área de domínio de leguminosas, fava d'anta (Dimorphandra mollis) e fava de bolota (Parkia platycephala), que os animais comem, a planta como reação a queima ela rebrota. Assim, o gado dispõe de forragem e água no período de estiagem, ainda que por meio de incêndios criminosos.

O sistema básico de manejo do solo da região é o sistema de corte e queima da vegetação. A agricultura de corte e queima pode gerar problemas como o desaparecimento de espécies de animais, o empobrecimento do solo e degradação ambiental em função da redução da vegetação nativa (FARIAS FILHO, 2006), especialmente quando há uma intensificação do uso dos solos com a consequente redução do tempo de pousio. No entanto, esse prejuízo é pequeno se comparado aos benefícios que o agricultor recebe. O sistema de corte e queima quando planejado é benéfico ao agricultor, não tendo todo o impacto prejudicial, mas deve ser controlado no que diz respeito ao uso constante da queima e quando ultrapassa a área queimando mais do que o previsto. Por exemplo, no corte e queima da vegetação, em uma única etapa da queima, o agricultor elimina diversos problemas que ele teria ao longo do ciclo produtivo. A limpeza do terreno proporciona a correção do pH do solo e eliminação das ervas espontâneas (ervas daninhas).

Outra prática utilizada pelos moradores do local é o manejo de corte seletivo da vegetação. O procedimento dá-se com a retirada de parte das árvores para evitar o empobrecimento completo do solo. Isso permite que 
o gado bovino transite e que a gramínea cresça sem sofrer com o estresse hídrico ou competição com a vegetação nativa.

\section{Considerações Finais}

No Balneário predominam os Latossolos Amarelos, Planossolos e Plintossolos. Tem sua economia baseada na fabricação de cerâmica, além da prática da pesca e pouca pecuária. Em razão de o solo ser rico em caulinita verifica-se uma suscetibilidade a inundação. A vegetação caracteriza-se por árvores de pequeno porte com caules retorcidos e folhas grosseiras típicas do cerrado. Há predomínio do babaçu devido ao manejo do solo por roça e pastagem de gado. As áreas onde há pouca vegetação verifica-se solo pobre, o qual também recebe influência pela incidência da radiação solar. Onde o solo recebe mais insolação o nível de intemperismo é mais elevado, perda maior de água e a matéria orgânica que se forma tem menor durabilidade com vegetação de menor porte. Atualmente, possui como atividade industrial mais expressiva a cerâmica. Além da atividade ceramista, há também práticas agropecuárias e extrativismo, especialmente o do babaçu. A pecuária está voltada principalmente para a atividade extensiva, destinada ao corte, com expressiva representação dos rebanhos caprinos e ovinos.

\section{Bibliografia}

CORREIA FILHO, F. L. et al. Projeto Cadastro de Fontes de Abastecimento por Água Subterrânea, estado do Maranhão: relatório diagnóstico do município de Vargem Grande. - Teresina: CPRM - Serviço Geológico do Brasil, 2011.

CORREIA FILHO. F. L. Projeto Avaliação de Depósitos Minerais para a Construção Civil PI/MA. Teresina: CPRM, 1997. v.1.

EMBRAPA. Sistema brasileiro de classificação de solos. 2. ed. - Rio de Janeiro: EMBRAPA-SPI, 2006.

FARIAS FILHO, M. S. Caracterização e Avaliação do Cultivo do Arroz em Sistema de Vazante na Baixada Maranhense. 2006. 128 f. Dissertação (Mestrado em Agroecologia) - Universidade Estadual do Maranhão, São Luís.

IBGE. Censo 2010. Disponível em: <http://www.cidades.ibge.gov.br/xtras/perfil.php?lang=\&codmun=211270\&search=maranhao|vargem-grande>. Acesso em: 28 ago. 2016. 


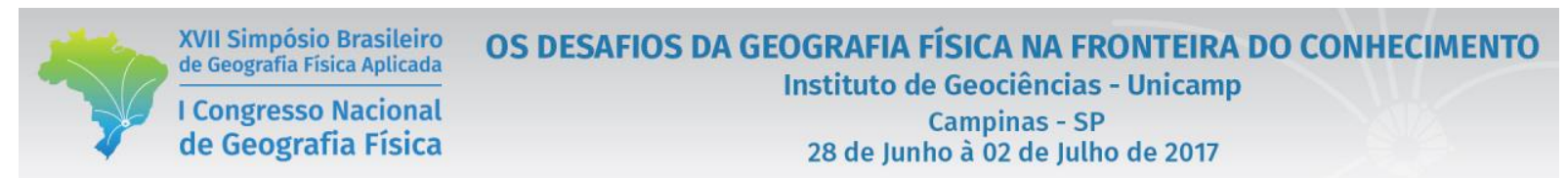

JACOMINE, P. K. T. et al. Levantamento exploratório-reconhecimento de solos do Estado do Maranhão. Rio de Janeiro, EMBRAPA-SNLCS/SUDENE. DRN, 1986. 